
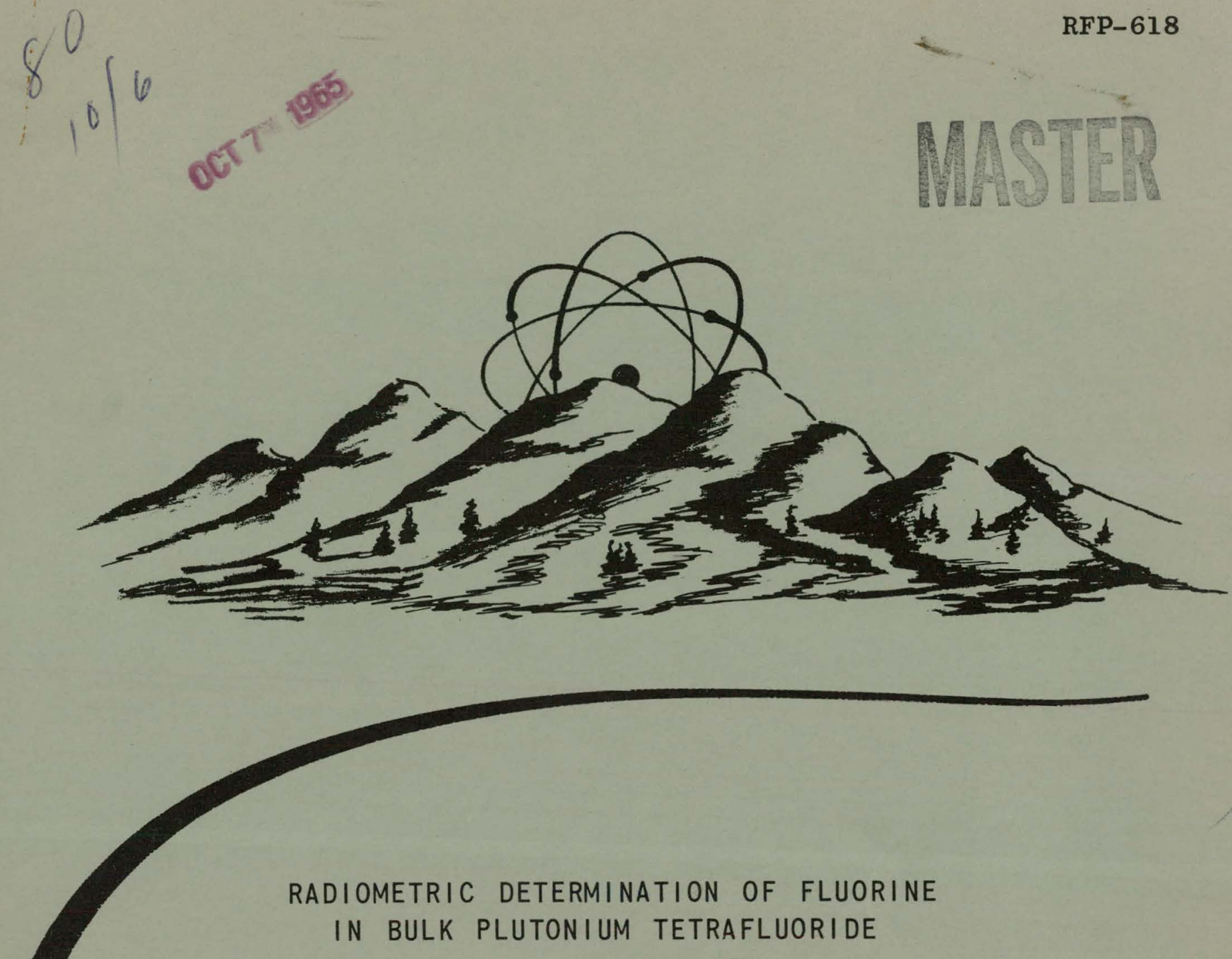

by

E. C. Long

O. H. Willoughby

D. R. Cartwright



THE DOW CHEMICAL COMPANY

ROCKY FLATS DIVISION

U.S. ATOMIC ENERGY COMMISSION

CONTRACT AT $(29-1)-1106$ 


\section{DISCLAIMER}

This report was prepared as an account of work sponsored by an agency of the United States Government. Neither the United States Government nor any agency Thereof, nor any of their employees, makes any warranty, express or implied, or assumes any legal liability or responsibility for the accuracy, completeness, or usefulness of any information, apparatus, product, or process disclosed, or represents that its use would not infringe privately owned rights. Reference herein to any specific commercial product, process, or service by trade name, trademark, manufacturer, or otherwise does not necessarily constitute or imply its endorsement, recommendation, or favoring by the United States Government or any agency thereof. The views and opinions of authors expressed herein do not necessarily state or reflect those of the United States Government or any agency thereof. 


\section{DISCLAIMER}

Portions of this document may be illegible in electronic image products. Images are produced from the best available original document. 


\section{LEGAL NOTICE}

This report was prepared as an account of Government sponsored work. Neither the United States, nor the Commission, nor any person acting on behalf of the Commission:

A. Makes any warranty or representation, expressed or implied, with respect to the accuracy, completeness, or usefulness of the information contained in this report, or that the use of any information, apparatus, method, or process disclosed in this report may not infringe privately owned rights; or

B. Assumes any liabilities with respect to the use of, or for damages resulting from the use of any information, apparatus, method, or process disclosed in this report.

As used in the above, "person acting on behalf of the Commission" includes any employee or contractor of the Commission, or employee of such contractor, to the extent that such employee or contractor of the Commission, or employee of such contractor prepares, disseminates, or provides access to, any information pursuant to his employment or contract with the Commission, or his employment with such contractor.

Printed in USA. Price $\$ 1$. Available from the Clearinghouse for Federal Scientific and Technical Information, National Bureau of Standards, U. S. Department of Commerce, Springfield, Virginia 


\title{
RADIOMETRIC DETERMINATION OF FLUORINE \\ IN BULK PLUTONIUM TETRAFLUORIDE
}

\author{
by \\ E. C. Iong \\ O. H. Willoughby \\ D. R. Carlwright
}




\section{ABSTRACT}

A radiometric instrument has been developed for the determination of the fluoride content in kilogram quantities of impure or nonstoichiometric plutonium tetrafluoride. The radiometric analytical results indicate an accuracy and precision comparable to the fluoride results obtained by the pyrohydrolytic. method: The special features of the instrument involve reduced time for the analysis and elimination of sampling error with bulk quantities of the material. 


\section{INTRODUCTION}

A rapid analysis of the fluoride content of plutonium tetrafluoride may be performed by detecting the neutron flux emitted from the material.

The total neutron flux of the tetrafluoride is a function of two major variables. These are the plutonium-240 content, and the extent of the $\alpha, n$ reaction on the fluoride given by the following equations:

$$
\begin{aligned}
& { }_{94} \mathrm{Pu}^{239} \rightarrow{ }_{92} \mathrm{U}^{235}+\alpha \\
& 9 F^{19}(\alpha, n){ }_{11} \mathrm{Na}^{22}
\end{aligned}
$$

(The $\mathrm{Na}^{22}$ subsequently decays by positron emission to $\mathrm{Mg}^{22}$, but is not important for this consideration.)

The relative importance of these two variables may be determined by a consideration of the neutron flux resulting from each. Plutonium240 has a reported spontaneous fission specific activity of 452 fissions/gm-sec. 2) For any reasonably pure plutonium with a five percent plutonium-240 content, a neutron emission rate of about 50 neutrons/gm-sec could be expected. An experimental value of about $1 \times 10^{4}$ neutrons/gm-sec has been obtained with plutonium tetrafluoride. (3) The plutonium-240 contribution then is about $1 / 200$ that of the $\alpha, n$ reaction, and may be compensated if necessary or may be neglected.

(1) J. L. Pflug, "Determination of Fluoride in Plutonium Tetrafluoride," Rocky Flats Internal Report AMD 463-2, February 1961.

(2) M. J. Steindler, "Radiation Problems Associated with the Handling of the Actinide Elements," USAEC Report, ANL-6540 (1962).

(3) D. E. Hankins, "An Energy Measurement of PuF 4 Neutrons and the Neutron Dose Rate from $\mathrm{PuF}_{4}$ Processing Equipment," USAEC Report LAMS-2692 ( 1962). 
Theory predicts that the neutron flux is not only a function of the fluoride content, but also a function of the concentration of any alpha emitter which lies sufficiently close to a fluorine atom so that the alpha particle would still possess at least the reaction threshold energy, about $2.3 \mathrm{Mev}$. A special requirement of nearly constant isotopic composition must be imposed upon process plutonium in order to eliminate or minimize variations in the alpha emission rates. Particular emphasis is to be placed upon the plutonium-238 and plutonium-240 ratios with respect to plutonium-239.

Within the limitations mentioned, the neutron tilux shows a proportionality to the fluoride concentration and an instrument can be constructed to measure this dependence.

\section{SUMMARY}

A radiometric instrument has been developed to perform rapid analyses of the fluoride content in bulk quantities $(0.5 \mathrm{~kg}$ to $4 \mathrm{~kg})$ of plutonium tetrafluoride. A special geometry and counting equipment .. are used to detect neutrons originating from the $\alpha, n$ reaction on the fluoride. Interference from other neutron sources and from high neutron background are negligible. The entire counting assembly is easily transportable which facilitates locating the instrument near fluoride production areas. The results indicate a relative standard deviation of 0.31 percent for the radiometric fluoride analysis, with an accuracy comparable to the standard analyses performed by a pyrohydrolytic method.

\section{DESIGN OF' I'HE APPARAIUS}

\section{DESCRIPTION}

The neutron detecting geometry consists of a block of polyethylerie measuring 28-inches wide by 50-inches long by 36-inches high, with a 10-inch diameter vertical well located in the center of the top. This well will accept an aluminum cylinder which can hold up to 4000 grams of plutonium tetrafluoride (See Figure 1). 


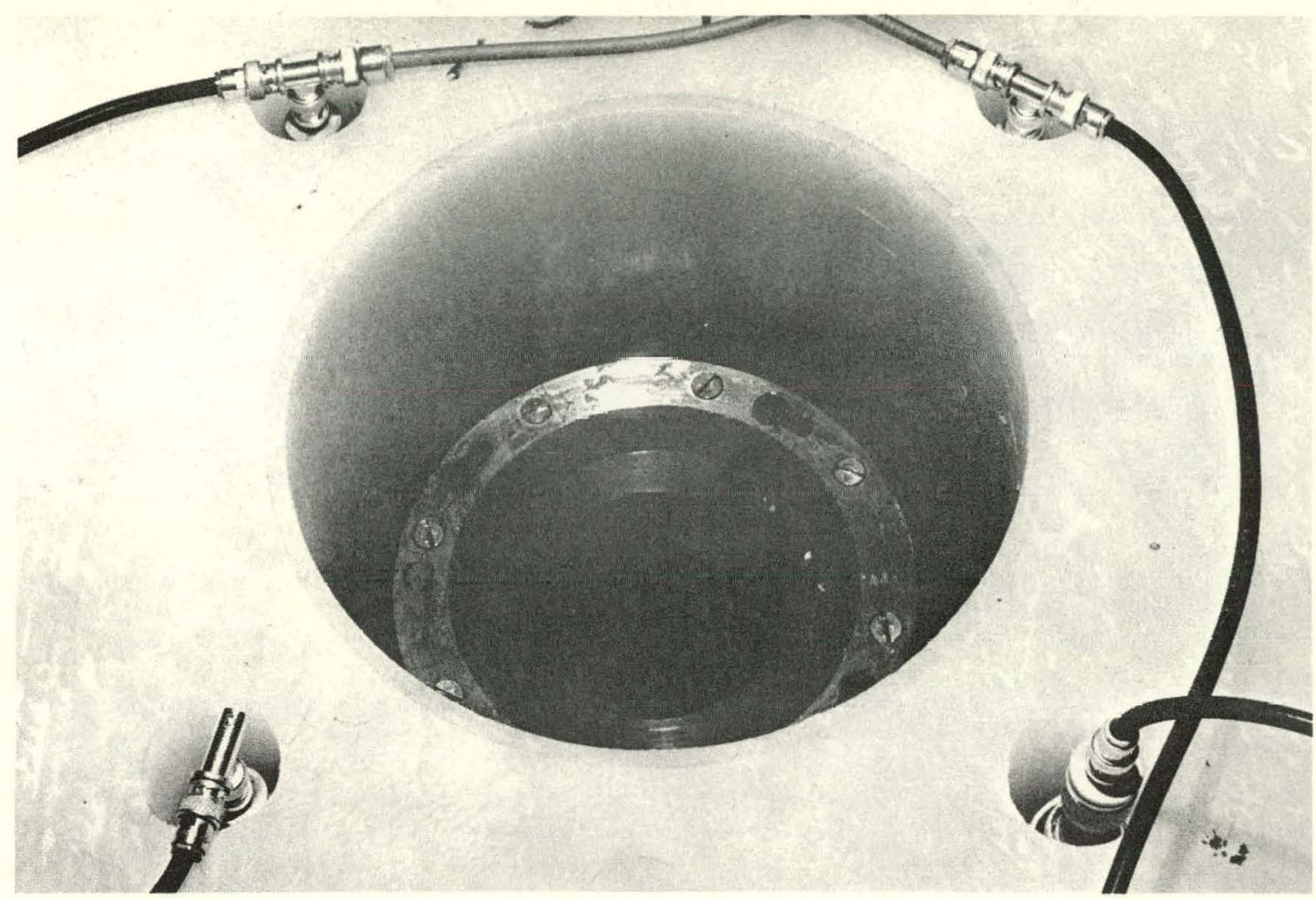

Figure 1. SAMPLE WELL AND DETECTORS

$10467-3$

Four 1- by 30-inch $\mathrm{BF}_{3}$ counting tubes are located concentrically around the sample well so that about 2-inches of polyethylene moderation are obtained with respect to the sample position. A minimum of 8 -inches of moderation exists with respect to the exterior of the polyethylene block (See Figure 2). Each $\mathrm{BF}_{3}$ tube is inserted into a vertical hole in the polyethylene block. Each hole is lined with $1 / 16$-inch cadmium sheet. The $\mathrm{BF}_{3}$ tubes are then clad with a i/8-inch thick layer of polyethylene moderator before their actual installation in the cadmium-lined holes (See Figure 3).

All four detection tubes are connected in parallel to both a highvoltage power supply and a preamplifier. A conventional singlechannel scintillation spectrometer with both integral and differential counting capabilities accepts pulses from the preamplifier and gives a count read-out on a scaler. 




Figure 2. NEUTRON DETECTING GEOMETRY

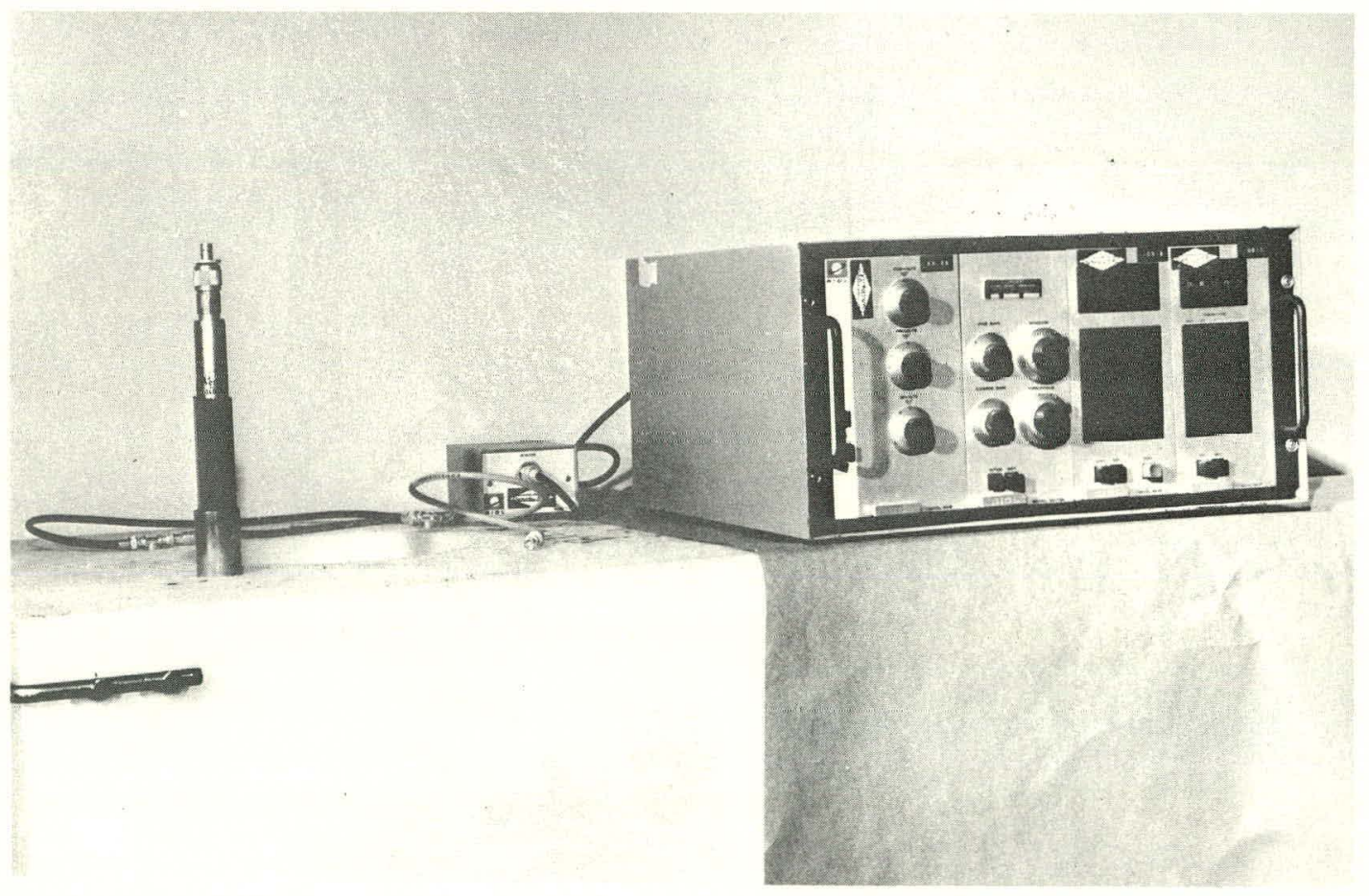

Figure 3. MODERATOR AND SHIELDING FOR DETECTORS 


\section{DISCUSSION}

The polyethylene block serves three primary functions. It acts as a physical structure to hold the detecting components in a fixed relationship to the sample, it serves as a moderator, and it shields against high neutron backgrounds.

As there are about $10^{3}$. neutrons per gram per second emitted from $\mathrm{PuF}_{4}(3)$, kilogram quantities desired for the analysis would yield up to $10^{7}$ neutrons per second. Fluxes of this magnitude would greatly exceed the counting capability of the conventional $\mathrm{BF}_{3}$ tube which has an experimentally determined dead time of 25 micro-seconds. The moderator-cadmium-moderator configuration has been chosen to give a definite efficiency for the apparatus and to minimize background interferences. Two inches of polyethylene between the sample and each detector serve to remove the detector a distance from the neutron source and to thermalize a quantity of the fast neutrons. At this distance, when both the inverse square law and moderation ratio of neutrons are considered, about 0.1 percent of the total emitted neutrons may be detected by an individual. $\mathrm{BF}_{3}$ tube. (4) Another attenuation factor of 5 is obtained by placing the cadmium layer at this point, and then an additional 1/8-inch thickness of moderator.

The experimentally measured efficiency of the $4 \mathrm{BF}_{3}$ detectors with respect to the total emitted neutron flux is about 0.08 percent which corresponds to approximately 1 percent dead time losses encountered for each $\mathrm{BF}_{3}$ detector.

Fast neutrons exterior to the system as a background are nearly all thermalized by the 8 -inches of moderator radially out from the detectors and are absorbed by the cadmium shielding for prevention of their detection or interference. (5)(6).

(4) F.R. Jones, "Shields for Neutron Sources," USAEC Report HW-21169( 1950).

(5) G. Friedlander, J.W. Kennedy, and J. M. Miller, Nuclear and Radiochemistry, John Wiley and Sons; Inc., New York (2nd Ed.) $117(1964)$.

(6) B. G. Harvey, Introduction to Nuclear Physics and Chemistry, Prentice-Hall, Inc., Englewood Cliffs, N.J., 233(1962). 


\section{OPERATIONAL CHARACTERISTICS}

A spectrum of plutonium tetrafluoride positioned in the vertical center of the sample well was taken differentially with the singlechannel spectrometer. The results are shown in Figure 4 .

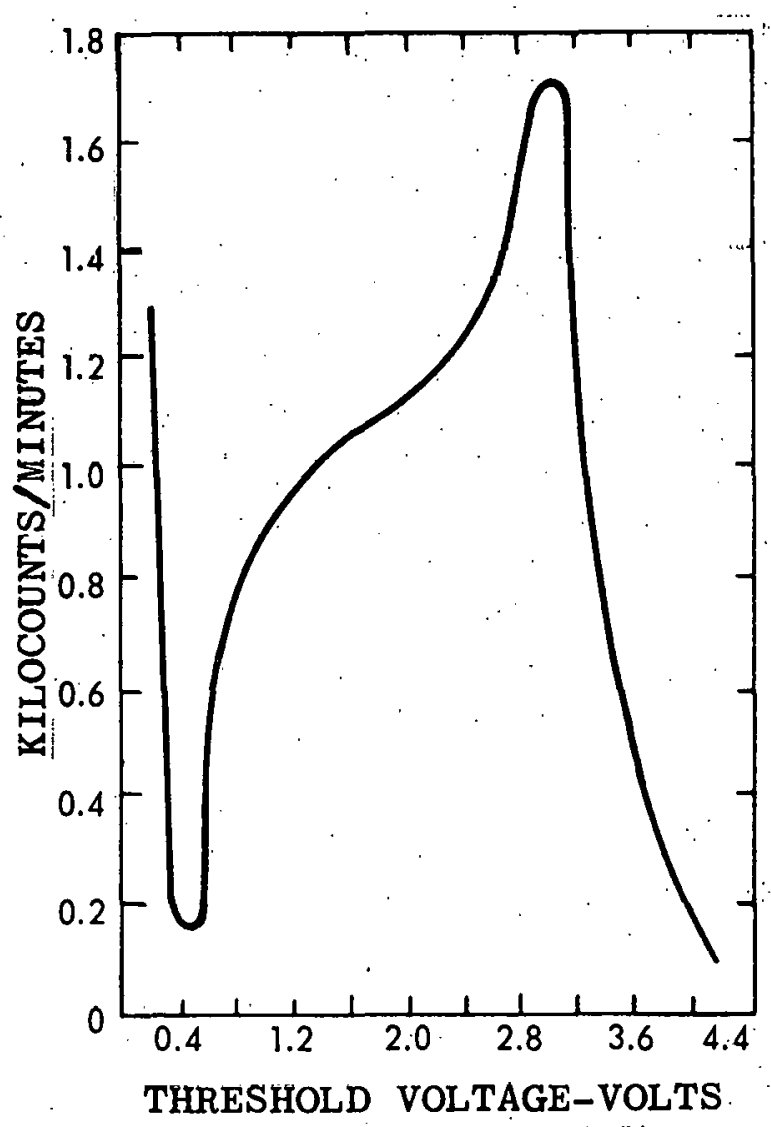

Figure 4. ENERGY RESPONSE OF BF $_{0}$ DETECTORS TO NEUTRONE

FROM PuF 4

From these data it may be seen that a range of pulse energies representing neutrons were observed from the $\mathrm{BF}_{3}$ detectors coupled in parallel. In order to record a total count, the lower threshold of the analyzer was set at the minimum point of the spectrum which. represents an energy value above amplifier noise and any low energy gamma radiation ( $\mathrm{BF}_{3}$ tubes are gamma sensitive), but below the thermal neutron pulses. Integral counts from this threshold value were then taken and recorded for the analysis. 
The sensitivity of the instrument to background neutrons was observed by placing the detection assembly in a high neutron background area measured at 300 . neutrons per square centimeter per second. The observed background counting rate was not changed. An additional check on the background was performed by bringing 20,000 grams of $\mathrm{PuF}_{4}$ to within 10 -feet of the assembly with no appreciable change in" the instrument counting rates.

Quantities of americium oxide and plutonium metal placed in the sample well verified that the gamma radiation sensitivity of the $B_{3}$ detectors was below the analyzer threshold voltage selected for integral counting.

Calibration and performance evaluations of the instrument were made by observing the neutron count from selected bulk samples of plutonium tetrafluoride which had been analyzed by a pyrohydrolytic method. The selected samples covered a range of fluoride concentrations from 13 to 21 percent. A sealed $\mathrm{PuF}_{4}$ steady-state source of neutrons with a flux of $10^{6}$ neutrons per second was referenced to the standard fluoride samples and was used to determine any drifts or changes in the single-channel analyzer settings.

\section{EXPERIMENTAL RESUITS}

The radiometric fluoride analyses were performed by inserting bulk samples of plutonium tetrafluoride into the well in the polyethylene block. A sample size of 2171 grams was used.

The results of several analyses and the correlation with standard laboratory analyses are given in Table $I$. The data given in the "Average Neutron Counts" column represents the average of from 3 to 6 repetitive counts for each number of counts listed. 
TABLE I

RESULTS OF RADIOMETRIC FLUORIDE ANALYSES

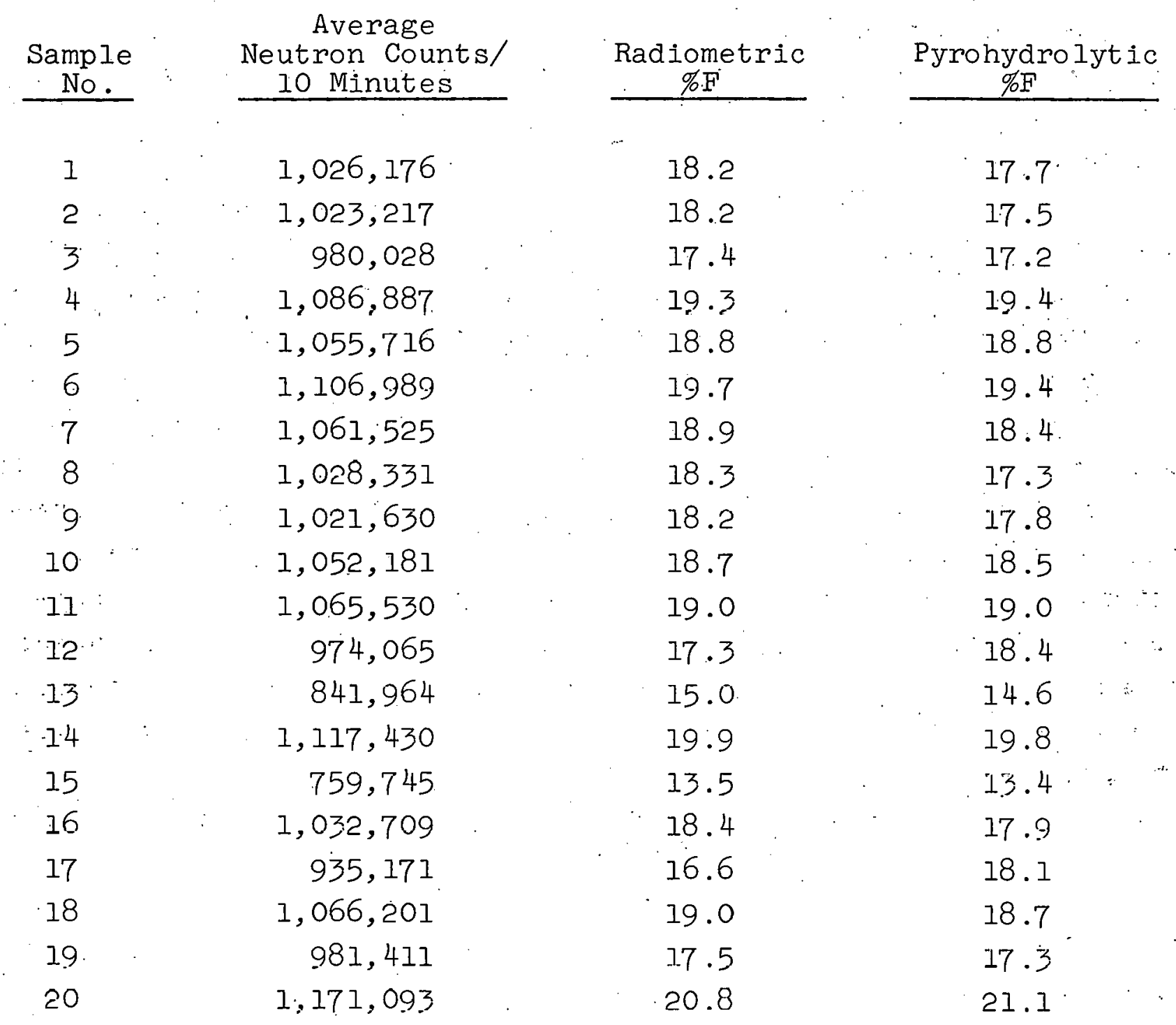

The simple equation used to calculate the fluoride content is as. follows:

$$
\% \mathrm{~F}=\frac{\mathrm{C}_{\mathrm{X}}}{\mathrm{C}_{\mathrm{S}}} \% \mathrm{~F}_{\mathrm{S}}
$$

where:

$$
\mathrm{C}_{\mathrm{x}}=\text { the number of neutron counts from the unknown sample per unit }
$$


$\begin{aligned} \mathrm{C}_{\mathrm{s}}= & \text { the number of neutron counts from a standard sample per unit } \\ & \text { time }\end{aligned}$

$\mathscr{F F}_{\mathrm{S}}=$ the percent fluoride of a standard sample.

(Note: For the data given in Table I, a sample of plutonium tetrafluoride weighing.2171 grams and analyzed at 21.0 percent was used as the standard. This sample had an average count of 1,179,665 for 10 minutes based on 10 determinations.)

An indication of the radiometric method precision is given in Table II. For these data a sample of plutonium tetrafluoride weighing 2171 grams has been repeatedly counted at intervals spanning 8 days.

TABLF: TI

PRECISION OF THE FLUORIDE ANALYSIS

$\begin{array}{ccc}\text { Date } & \begin{array}{c}\text { Neutron Counts/ } \\ 10 \text { Minutes }\end{array} & \begin{array}{c}\% \mathrm{~F} \\ \text { Calculated }\end{array} \\ 12 / 10 / 64 & 1,035,985 & 18.44 \\ & 1,034,410 & 18.41 \\ 1,032,424 & 18.38 \\ & 1,034,166 & 18.41 \\ & 1,033,350 & 18.40 \\ 12 / 11 / 64 & 1,034,218 & 18.41 \\ & 1,041,995 & 18.55 \\ 12 / 17 / 64 & 1,039,691 & 18.51 \\ & 1,040,547 & 18.53 \\ & 1,041,051 & 18.53 \\ & 1,037,348 & 18.47 \\ & 1,039,477 & 18.50 \\ & 1,041,568 & 18.55 \\ & 1,040,242 & 18.52 \\ & 1,039,193 & 18.50 \\ & 1,039,038 & 18.50 \\ & 1,037,846 & 18.48\end{array}$


A statistical evaluation of the data presented in Table I revealed: that the radiometric method was as accurate as the pyrohydrolytic method for determining the fluoride content in plutonium tetrafluoride. The relative standard deviation for the fluoride determination on typical data as presented in Table II was 0.31 percent. 